JURNAL ILMIAH AGRINECA

ISSN : 2721-074X (Online) - 2301-6698 (Print)

Available on : http://ejournal.utp.ac.id/index.php/AFP/index

This is Under CC BY SA Licence

\title{
KESESUAIAN BERBAGAI VARIETAS PADI SAWAH PADA BUDIDAYAORGANIK
}

\author{
COMPATIBILITY VARIETIES OF PADDY ON ORGANIC \\ CULTURE
}

\author{
Achmad Fatchul Aziez* \\ Program Studi Agroteknologi, Fakultas Pertanian, Universitas Tunas \\ Pembangunan Surakarta \\ E-mail : achmad.aziez@yahoo.com
}

\begin{abstract}
Rice varieties are very abundant but each variety has different agronomic and physiological characteristics. Not all varieties are suitable for organic cultivation. The purpose of this study is to find varieties that are suitable for organic cultivation. This research has been carried out in a greenhouse in the experimental garden of the Faculty of Agriculture, Gadjah Mada University with Inceptisol soil. The experiment was designed with a $15 \times 2$ factorial Completely Randomized Design with 3 replications. The treatment consists of two factors. The first factor is the method of cultivation, namely organic cultivation and conventional cultivation and factor II is the type of wetland rice varieties consisting of 15 varieties consisting of Mentikwangi, Mentiksusu, Pandanwangi, Rojolele, Cianjur, Pelita, Remaja, IR64, Situbagendit, Cisedane, Ciherang, Inpari, Gilirang, Cimelati and Fatmawati. Data analysis was carried out using the SAS 9.0 program. The results showed that Mentikwangi, Pelita I-1 and Fatmawati varieties produced grain weight which increased when cultivated organically.
\end{abstract}

Keyword : conventional culture, organic culture, paddy, variety

\section{ABSTRAK}

Varietas padi sawah sangat banyak namun setiap varietas mempunyai karakter agronomi dan fisiologi yang berbeda. Tidak semua varietas sesuai untuk dibudidayakan secara organik. Tujuan dari penelitian ini adalah untuk mencari varietas yang memang sesuai untuk budidaya secara organik.Penelitian ini telah dilaksanakan di rumah kaca di kebun percobaan Fakultas Pertanian Universitas Gadjah Mada dengan tanah Inceptisol. Percobaan dirancang dengan Rancangan Acak Lengkap (RAL) faktorial 15x2 dengan 3 ulangan. Perlakuan terdiri atas dua faktor. Faktor I adalah cara budidaya yaitu budidaya organik dan budidaya konvensional dan faktor II adalah macam varietas terdiri 15 varietas yaitu Mentikwangi, Mentiksusu, Pandanwangi, Rojolele, Cianjur, Pelita Remaja, IR64, Situbagendit, Cisedane, Ciherang, Inpari, Gilirang, Cimelati dan Fatmawati. Analisis data dilakukan dengan menggunakan program SAS 9.0. Hasil penelitian menunjukan bahwa Varietas Mentikwangi, Pelita I-1 dan Fatmawati menghasilkan berat gabah yang meningkat bilamana dibudidayakan secara organik.

Kata Kunci :budidaya organik, budidaya konvensional, padi, varietas

\section{PENDAHULUAN}

Peningkatan produktivitas tanaman padi tercapai setelah adanya revolusi hijau (green revolution) (Hasanuzzaman et al.,
2010) yaitu dengan dilaksanakannya sistem pertanian modern antara lain dengan penggunaan sejumlah besar pupuk anorganik (Ali, 2016), pestisida dan herbisida anorganik (Khan et al., 2007). Di Indonesia penerapan sistem pertanian modern adalah dengan dilaksanakannya Panca Usaha Tani seperti adanya 
JURNAL ILMIAH AGRINECA

ISSN : 2721-074X (Online) - 2301-6698 (Print)

Available on : http://ejournal.utp.ac.id/index.php/AFP/index

This is Under CC BY SA Licence

penggunaaan pupuk anorganik dan penggunaan pestisida anorganik sehingga Indonesia pada tahun 1980 bisa swasembada padi.

Dampak negatif adanya penggunaan pupuk anorganik yang berlebihan akan menyebabkan pelandaian produktivitas tanaman, kemerosotan sifat-sifat tanah (Hasanuzzaman et al., 2010), percepatan erosi tanah, penurunan kualitas tanah dan kontaminasi air bawah tanah (Allen and Van Dusen, 1988 ; Ikemura and Shukla, 2009). Sistem pertanian yang berbasis bahan high input energy (bahan fosil) seperti pupuk anorganik dan pestisida dapat merusak sifat-sifat tanah dan akhirnya menurunkan produktivitas tanah untuk waktu yang akan datang (Ikemura and Shukla, 2009 ; Sanati et al., 2011).

Kondisi pupuk organik yang kadar haranya rendah dan lambat tersedia mengakibatkan tidak semua varietas padi sawah sesuai untuk dibudidayakan dalam sistem pertanian organik. Varietas padi sawah yang meliputi varietas lokal, varietas unggul lama, varietas unggul baru dan varietas unggul tipe baru (VUTB) mempunyai karakter fisiologis dan pertumbuhan yang berbeda sehingga kesesuaian hasil dalam sistem pertanian organik juga akan berbeda.

Penerapan budidaya organik di tingkat petani pada umumnya menggunakan varietas lokal, sedang penggunaan varietas unggul jarang sekali dilakukan. Informasi tentang varietas apa yang sesuai untuk budidaya organik, karakter apa saja yang menentukan kesesuaiannya pada budidaya organik dan bagaimana mekanisme kesesuaiannya terhadap sistem pertanian organik masih sangat terbatas. Oleh karena itu penelitian tentang kesesuaian varietas padi sawah pada budidaya secara organik perlu dilakukan. Adapun tujuan dari penelitian ini adalah untuk mendapatkan varietas padi sawah yang memang sesuai untuk budidaya organik

\section{METODE PENELITIAN}

Percobaan dilaksanakan dirumah kaca di kebun percobaan Fakultas Pertanian Universitas Gadjah Mada Banguntapan, Berbah, Sleman dengan ketinggian tempat $113 \mathrm{~m}$ dpl dengan jenis tanah inceptisol. Percobaan berlangsung pada musim penghujan, bulan Oktober 2012 sampai dengan Februari 2013. Bahan yang digunakan pada percobaan antara lain benih padi sebanyak 15 varietas (Hariyadi, Huda, Ali, \& Wandik, 2019). Varietas yang terpilih sebagai perlakuan berasal dari Balai Besar Penelitian Tanaman Padi di Sukamandi. Tanah Inceptisol untuk budidaya organik diambil dari sawah yang sudah digunakan untuk budidaya padi secara organik selama lebih 8 tahun sedangkan tanah untuk budidaya konvensional diambil dari lahan sawah untuk budidaya konvensional terus menerus lebih 10 tahun dari desa Kebonagung, kecamatan Imogiri, kabupaten Bantul. Sampel tanah diambil secara komposit yang mewakili setiap areal percobaan (Anonymous, 2007). Bahan-bahan penelitian yang lain adalah pupuk urea, SP36, $\mathrm{KCl}$, pupuk organik (kompos kandang sapi), pestisida organik dan anorganik. Alat yang dipergunakan antara lain bak pesemaian, pot/ember, timbangan analitik, penumbuk, saringan tanah, oven, kamera digital, alat tulismenulis dan komputer.

Percobaan dirancang dengan Rancangan Acak Lengkap (RAL) faktorial $15 \times 2$ dengan 3 ulangan. Perlakuan terdiri atas dua faktor. Faktor I adalah cara budidaya yaitu budidaya organik dan budidaya konvensional dan faktor II adalah macam varietas padi sawah terdiri 15 varietas yang terdiri dari Mentikwangi, Mentiksusu, Pandanwangi, Rojolele, Cianjur, Pelita,Remaja, IR64, Situbagendit, Cisedane, Ciherang, Inpari Gilirang, Cimelati dan Fatmawati

Benih padi kelima belas varietas direndam sehari semalam sebelum tanam 
JURNAL ILMIAH AGRINECA

ISSN : 2721-074X (Online) - 2301-6698 (Print)

Available on : http://ejournal.utp.ac.id/index.php/AFP/index

This is Under CC BY SA Licence

dan benih yang tenggelam disemaikan pada bak plastik ukuran $30 \mathrm{~cm} \times 40 \mathrm{~cm}$. Bibit yang berumur 21 hari dipindah tanam ke dalam media pot/ember masingmasing satu bibit per pot

Untuk budidaya organik diberikan kompos kandang sapi takaran 47,1 g/pot (15 ton/ha) dan dicampur dengan tanah sebelum dimasukkan dalam pot dan untuk budidaya konvensional diberikan pupuk $\mathrm{N}$ sebanyak $800 \mathrm{mg} /$ pot urea $(250 \mathrm{~kg} / \mathrm{ha})$, pupuk P sebanyak $310 \mathrm{mg} /$ pot SP36 (100 $\mathrm{kg} / \mathrm{ha}$ ) dan pupuk K sebanyak $240 \mathrm{mg} /$ pot $\mathrm{KCl}(75 \mathrm{~kg} / \mathrm{ha}$ )(sesuai dosis lokasi tanah asal). Pupuk urea diberikan 3 tahap masing-masing $1 / 3$ dosis pada umur 1,6 dan 8 minggu, sedangkan pupuk $\mathrm{P}$ dan $\mathrm{K}$ diberikan sekaligus saat tanam. Pupuk anorganik diberikan dengan cara disebar. Penghitungan dosis pupuk disajikan pada lampiran 40. Penggantian tanaman yang mati atau pertumbuhan tanaman kurang baik dilakukan dengan cara menyulamnya pada umur 7 HST menggunakan bibit cadangan. Pengendalian hama dan penyakit untuk budidaya organik digunakan ekstrak jengkol dengan cara 5 biji jengkol diparut, kemudian direndam dengan 1 liter air selama semalam, paginya ekstrak jengkol dilarutkan dengan 14 liter air, dan siap untuk mengendalikan hama dan penyakit. Untuk budidaya konvensional dengan pestisida anorganik dengan konsentrasi 2 cc/liter air.Penyiangan gulma dilakukan pada umur 3 dan 7 MST dengan cara mencabut gulma yang tumbuh dalam pot. Pemberian air dengan cara menggenangi sampai fase pembentukan malai penuh. Dua minggu sebelum panen tanah dibiarkan dalam kondisi macak-macak. Panen dimulai bila kulit biji pada bagian atas malai telah bersih dan keras serta $80 \%$ biji telah berwarna coklat jerami(IRRI, 1970). Variabel yang diamati adalah jumlah anakan produktif, jumlah malai per rumpun, panjang malai, jumlah gabah isi, berat 1000 gabah dan berat gabah kering panen. Hasil gabah setiap varietas diukur saat panen pada kadar air 14\%. Kadar air gabah diukur dengan menggunakan alat grain moisture tester. Pengukuran hasil gabah dilakukan dengan menimbang gabah seluruhnya pada setiap rumpun.

Pemilahan dan pemilihan varietas sesuai budidaya organik didasarkan pada berat gabah kering panen dengan metode pembobotan (skoring). Nilai pembobotan (skoring) selanjutnya dibuat rerata.

Penentuan banyak kelas interval dan panjang kelas interval dalam metode pembobotan ini mengikuti aturan Sturges (Sudjana, 1992). Banyak kelas interval (K) dan panjang kelas interval (P) ditetapkan dengan cara :

$\mathrm{K}=1+3,3 \log \mathrm{n}$, dimana $\mathrm{n}$ adalah banyaknya data

$\mathrm{P}=\mathrm{R} / \mathrm{K}$, dimana $\mathrm{R}$ adalah kisaran (nilai data terbesar-nilai data terkecil).

Tabel 1. Pengelompokkan varietas berdasarkan kesesuaiannya pada budidaya organik

\begin{tabular}{clcc}
\hline No. & \multicolumn{1}{c}{ Kelompok } & $\begin{array}{c}\text { Selisih hasil antara } \\
\text { budidaya konvensional } \\
\text { dengan budidaya } \\
\text { organik }\end{array}$ & $\begin{array}{c}\text { Kesesuaian } \\
\text { dengan budidaya } \\
\text { organik }\end{array}$ \\
\hline 1. & $\begin{array}{l}\text { Hasil tinggi, sesuai budidaya organik } \\
\text { Hasil tinggi, tidak sesuai budidaya } \\
\text { organik }\end{array}$ & Kecil & Sesuai \\
Besar & Tidak sesuai \\
3. & $\begin{array}{l}\text { Hasil rendah, sesuai budidaya } \\
\text { organik }\end{array}$ & Sesuai \\
Hasil rendah, tidak sesuai budidaya & Besar & Tidak sesuai \\
\hline
\end{tabular}

Sumber: Analisis data primer 
JURNAL ILMIAH AGRINECA

ISSN : 2721-074X (Online) - 2301-6698 (Print)

Available on : http://ejournal.utp.ac.id/index.php/AFP/index

This is Under CC BY SA Licence

Data pengamatan dianalisis dengan metode pembobotan (skoring) dan sidik ragam (anova) menurut rancangan faktorial acak lengkap. Bila terdapat perbedaan diantara perlakuan maka diuji lanjut dengan menggunakan Duncan's New Multiple Range Test (DMRT) pada taraf nyata $5 \%$. Data dianalisis dengan perangkat komputer menggunakan program SAS for window 9.0 (SAS, 2002).

\section{HASIL DAN PEMBAHASAN}

Hasil analisis data terhadap variabel jumlah anakan produktif, jumlah malai per rumpun, panjang malai, jumlah gabah isi per malai, berat 1000 gabah dan berat gabah per rumpun menunjukkan interaksi antara varietas dengan cara budidaya. Hasil pengamatan terhadap jumlah anakan produktif, jumlah malai per rumpun, panjang malai, jumlah gabah isi per malai, berat 1000 gabah dan berat gabah per rumpun disajikan masing-masing pada Tabel 2, Tabel 3, Tabel 4,Tabel 5, Table 6, dan Tabel 7.

\section{Jumlah anakan produktif}

Anakan produktif adalah anakan yang menghasilkan malai. Berdasarkan hasil analisis data jumlah anakan produktif dipengaruhi interaksi antara varietas dengan carabudidaya (Tabel 2).

Jumlah anakan produktif varietas Pandanwangi pada budidaya organik lebih rendah dibandingkan jumlah anakan produktif budidaya konvensional, sedangkan varietas yang lain jumlah anakan produktif tidak berbeda. Jumlah anakan produktif selain dipengaruhi faktor genetik suatu varietas, juga dipengaruhi oleh faktor lingkungan (Horie et al., 2006). Rendahnya jumlah anakan produktif varietas Pandanwangi pada budidaya organik didukung oleh pernyataan Guswara (2003) bahwa tidak terciptanya keserasian antara varietas dan lingkungan pada sistem budidaya organik akan menyebabkan tidak mampunya fungsi fisiologis yang baik. Ditambahkan oleh Dobermann dan Fairhurst (2000) bahwa unsur fosfor sangat memegang peranan dalam proses pembentukan bulir dan juga pada fase pengisian bulir.

Tabel 2. Rerata jumlah anakan produktif 15 varietas padi sawah pada budidaya organik dan konvensional

\begin{tabular}{lcccc}
\hline \multirow{2}{*}{ Varietas } & \multicolumn{2}{c}{ Budidaya $(\mathrm{B})$} & $\begin{array}{c}\text { Peningkatan } \\
\text { dari Bk ke Bo (\%) }\end{array}$ & Rerata \\
\cline { 2 - 3 } & Konvensional (Bk) & $\begin{array}{c}\text { Organik } \\
\text { (Bo) }\end{array}$ & & 15,00 \\
Mentikwangi & $16,45 \mathrm{~b}-\mathrm{h}$ & $13,56 \mathrm{~d}-\mathrm{h}$ & $-17,57$ & 14,56 \\
Mentiksusu & $15,003 \mathrm{c}-\mathrm{h}$ & $14,11 \mathrm{c}-\mathrm{h}$ & $-6,12$ & 17,55 \\
Pandanwangi & $24,22 \mathrm{a}$ & $10,87 \mathrm{~h}$ & $-55,12$ & 11,17 \\
Rojolele & $11,00 \mathrm{gh}$ & $11,33 \mathrm{f}-\mathrm{h}$ & 3,00 & 19,22 \\
Cianjur & $21,22 \mathrm{ab}$ & $17,22 \mathrm{~b}-\mathrm{f}$ & $-18,85$ & 16,39 \\
Pelita I-1 & $15,00 \mathrm{c}-\mathrm{h}$ & $17,78 \mathrm{~b}-\mathrm{e}$ & 1,85 & 17,00 \\
Remaja & $18,78 \mathrm{a}-\mathrm{d}$ & $15,22 \mathrm{c}-\mathrm{h}$ & $-18,96$ & 20,89 \\
IR64 & $21,78 \mathrm{ab}$ & $20,00 \mathrm{a}-\mathrm{c}$ & $-8,17$ & 11,89 \\
Situbagendit & $12,44 \mathrm{e}-\mathrm{h}$ & $11,33 \mathrm{f}-\mathrm{h}$ & $-8,92$ & 16,39 \\
Cisedane & $15,89 \mathrm{~b}-\mathrm{h}$ & $16,89 \mathrm{~b}-\mathrm{h}$ & 6,29 & 14,22 \\
Ciherang & $17,11 \mathrm{~b}-\mathrm{g}$ & $11,33 \mathrm{f}-\mathrm{h}$ & $-33,78$ & 16,33 \\
Inpari13 & $16,56 \mathrm{~b}-\mathrm{h}$ & $16,11 \mathrm{~b}-\mathrm{h}$ & $-2,72$ & 14,16 \\
Gilirang & $15,11 \mathrm{c}-\mathrm{h}$ & $13,22 \mathrm{~d}-\mathrm{h}$ & $-12,51$ & 12,33 \\
Cimelati & $12,00 \mathrm{e}-\mathrm{h}$ & $12,67 \mathrm{e}-\mathrm{h}$ & 5,58 & 12,72 \\
Fatmawati & $12,67 \mathrm{e}-\mathrm{h}$ & $12,78 \mathrm{~d}-\mathrm{h}$ & 0,87 & $\mathbf{( + )}$ \\
\hline Rerata & $\mathbf{1 6 , 3 5}$ & $\mathbf{1 4 , 3 0}$ & &
\end{tabular}


JURNAL ILMIAH AGRINECA

ISSN : 2721-074X (Online) - 2301-6698 (Print)

Available on : http://ejournal.utp.ac.id/index.php/AFP/index

This is Under CC BY SA Licence

Keterangan : Angka yang diikuti huruf yang sama dalam baris dan kolom tidak berbeda nyata menurut DMRT 5\%. Tanda (+) menunjukkan ada interaksi.

\section{Jumlah malai per rumpun}

Malai merupakan komponen hasil utama tanaman padi.Jumlah malai berkorelasi positif terhadap hasil gabah (Hasanuzzaman et al., 2010).Jumlah malai ditentukan dari anakan yang berhasil membentuk malai dari anakan yang ada dan disebut sebagai anakan produktif.Jumlah malai pada tanaman padi ditentukan saat terjadinya inisiasi bunga yaitu pada selang waktu sekitar 30 hari sebelum keluarnya bunga (heading) (Hasanuzzaman et al., 2010).

Berdasarkan hasil analisis data jumlah malai per rumpun dipengaruhi interaksi antara varietas dengan cara budidaya (Tabel 3). Budidaya organik menurunkan jumlah malai per rumpun varietas Pandanwangi, Cianjur dan Ciherang. Pada budidaya konvensional jumlah malai terbanyak varietas Cianjur dan berbeda nyata dengan varietas yang lain kecuali varietas Pandanwangi dan IR64, namun pada budidaya organik jumlah malai terbanyak varietas IR64 dan berbeda nyata dengan varietas Pandanwangi, Rojolele, Situbagendit, dan Ciherang. Jumlah malai ditentukan oleh jumlah anakan produktif, semakin banyak jumlah anakan produktif maka jumlah malainya semakin banyak.Pada budidaya organik, varietas IR64 mempunyai jumlah anakan produktif (Tabel 2.) terbanyak sehingga menghasilkan jumlah malai terbanyak juga.Hal ini didukung oleh pernyataan Murayama (1995), jumlah malai per rumpun berkaitan erat dengan kemampuan tanaman menghasilkan anakan dan kemampuan mempertahankan berbagai fungsi fisiologis tanaman.Semakin banyak anakan yang terbentuk semakin besar peluang terbentuknya anakan yang menghasilkan malai.Pada saat tanaman mulai berbunga hampir seluruh hasil fotosintesis dialokasikan ke bagian generatif tanaman (malai) dalam bentuk tepung.Selain itu, terjadi juga mobilisasi karbohidrat, protein dan mineral yang ada di daun, batang dan akar untuk ditranslokasikan ke malai.

Tabel 3. Rerata jumlah malai 15 varietas padi sawah pada budidaya organik dan konvensional

\begin{tabular}{|c|c|c|c|c|}
\hline \multirow[t]{2}{*}{ Varietas } & \multicolumn{2}{|c|}{ Budidaya (B) } & \multirow{2}{*}{$\begin{array}{c}\text { Peningkatan } \\
\text { dari Bk ke Bo } \\
(\%)\end{array}$} & \multirow[t]{2}{*}{ Rerata } \\
\hline & $\begin{array}{c}\text { Konvensional } \\
\text { (Bk) }\end{array}$ & $\begin{array}{c}\text { Organik } \\
\text { (Bo) }\end{array}$ & & \\
\hline Mentikwangi & $16,47 \mathrm{c}-\mathrm{f}$ & $13,57 \mathrm{~d}-\mathrm{h}$ & $-2,90$ & 15,02 \\
\hline Mentiksusu & $15,03 \mathrm{c}-\mathrm{h}$ & $14,10 \mathrm{c}-\mathrm{h}$ & $-6,19$ & 14,57 \\
\hline Pandanwangi & $24,23 \mathrm{ab}$ & $8,20 \mathrm{~g}-\mathrm{h}$ & $-66,16$ & 16,22 \\
\hline Rojolele & $9,00 \mathrm{f}-\mathrm{h}$ & $8,33 \mathrm{~g}-\mathrm{h}$ & $-7,44$ & 8,67 \\
\hline Cianjur & $27,90 \mathrm{a}$ & $17,23 \mathrm{~b}-\mathrm{e}$ & $-38,24$ & 22,57 \\
\hline Pelita I-1 & $15,00 \mathrm{c}-\mathrm{h}$ & $17,80 \mathrm{~b}-\mathrm{e}$ & $+18,67$ & 16,40 \\
\hline Remaja & $18,77 \mathrm{~b}-\mathrm{d}$ & $15,20 \mathrm{c}-\mathrm{h}$ & $-19,02$ & 16,98 \\
\hline IR64 & $21,77 \mathrm{a}-\mathrm{c}$ & $20,00 \mathrm{~b}-\mathrm{d}$ & $-8,13$ & 20,88 \\
\hline Situbagendit & $12,43 \mathrm{~d}-\mathrm{h}$ & $10,67 \mathrm{e}-\mathrm{h}$ & $-14,16$ & 11,55 \\
\hline Cisedane & $15,87 \mathrm{c}-\mathrm{g}$ & $15,90 \mathrm{c}-\mathrm{g}$ & $+0,19$ & 15,88 \\
\hline Ciherang & $17,13 \mathrm{~b}-\mathrm{e}$ & $7,67 \mathrm{~h}$ & $-55,22$ & 12,40 \\
\hline Inpari13 & $16,57 \mathrm{~b}-\mathrm{f}$ & $16,10 \mathrm{c}-\mathrm{g}$ & $-2,84$ & 16,33 \\
\hline Gilirang & $15,10 \mathrm{c}-\mathrm{h}$ & $12,53 \mathrm{~d}-\mathrm{h}$ & $-17,02$ & 13,82 \\
\hline Cimelati & $12,00 \mathrm{~d}-\mathrm{h}$ & $12,00 \mathrm{~d}-\mathrm{h}$ & 0 & 12,00 \\
\hline Fatmawati & $12,03 \mathrm{~d}-\mathrm{h}$ & $12,80 \mathrm{~d}-\mathrm{h}$ & $+6,40$ & 12,42 \\
\hline Rerata & 16,62 & 13,47 & & $(+)$ \\
\hline
\end{tabular}


JURNAL ILMIAH AGRINECA

ISSN : 2721-074X (Online) - 2301-6698 (Print)

Available on : http://ejournal.utp.ac.id/index.php/AFP/index

This is Under CC BY SA Licence

Keterangan : Angka yang diikuti huruf yang sama dalam baris dan kolom tidak berbeda nyata menurut DMRT 5\%. Tanda (+) menunjukkan ada interaksi.

\section{Panjang malai}

Panjang malai tanaman padi merupakan salah satu indikator yang menentukan banyaknya biji yang terdapat pada malai.Semakin panjang malai biasanya jumlah biji pada malai semakin banyak.Translokasi fotosintat saat terjadinya inisiasi malai sebagian diarahkan untuk perpanjangan malai (Matsuo and Hoshikawa, 1993).

Berdasarkan hasil analisis data panjang malai dipengaruhi interaksi antara varietas dengan cara budidaya (Tabel 4).
Budidaya organik menyebabkan malai varietas Situbagendit dan Fatmawati lebih pendek, sedangkan panjang malai varietas yang lain tidak berbeda antara budidaya organik dengan budidaya konvensional. Hal ini mengindikasikan bahwa source organ dan fotosintesis varietas Situbagendit dan Fatmawati pada budidaya organik menurun. Menurut Abdullah (2008), pemanjangan malai dipengaruhi oleh kapasitas source organ dan juga dipengaruhi hasil fotosintesa. Translokasi hasil fotosintesis saat terjadinya inisiasi malai sebagian diarahkan untuk pemanjangan malai.

Tabel 4. Rerata panjang malai $(\mathrm{cm}) 15$ varietas padi sawah pada budidaya organik dan konvensional

\begin{tabular}{llccc}
\hline \multicolumn{1}{c}{ Varietas } & \multicolumn{2}{c}{ Budidaya (B) } & $\begin{array}{c}\text { Peningkatan } \\
\text { dari Bk ke Bo } \\
(\%)\end{array}$ & Rerata \\
\cline { 2 - 3 } & $\begin{array}{c}\text { Konvensional } \\
(\mathrm{Bk})\end{array}$ & $\begin{array}{c}\text { Organik } \\
(\mathrm{Bo})\end{array}$ & 3,51 & \\
\hline Mentikwangi & $25,33 \mathrm{~b}-\mathrm{f}$ & $26,22 \mathrm{a}-\mathrm{d}$ & 25,78 \\
Mentiksusu & $23,55 \mathrm{~d}-\mathrm{j}$ & $24,22 \mathrm{~d}-\mathrm{j}$ & 2,85 & 23,89 \\
Pandanwangi & $24,67 \mathrm{~d}-\mathrm{h}$ & $24,89 \mathrm{~d}-\mathrm{h}$ & 0,89 & 24,78 \\
Rojolele & $28,89 \mathrm{a}$ & $28,00 \mathrm{a}-\mathrm{c}$ & $-3,08$ & 28,44 \\
Cianjur & $19,33 \mathrm{k}-\mathrm{m}$ & $19,00 \mathrm{~lm}$ & $-1,71$ & 19,17 \\
Pelita I-1 & $24,22 \mathrm{~d}-\mathrm{h}$ & $21,78 \mathrm{~h}-1$ & $-10,07$ & 23,00 \\
Remaja & $21,89 \mathrm{~h}-1$ & $22,89 \mathrm{e}-\mathrm{j}$ & 4,57 & 22,39 \\
IR64 & $21,33 \mathrm{i}-1$ & $25,11 \mathrm{c}-\mathrm{g}$ & 17,72 & 23,22 \\
Situbagendit & $21,33 \mathrm{i}-1$ & $17,66 \mathrm{~m}$ & $-17,21$ & 19,50 \\
Cisedane & $20,45 \mathrm{j}-1$ & $19,00 \mathrm{~lm}$ & $-7,09$ & 19,72 \\
Ciherang & $24,78 \mathrm{~d}-\mathrm{h}$ & $25,67 \mathrm{~b}-\mathrm{e}$ & 3,59 & 25,22 \\
Inpari13 & $21,22 \mathrm{i}-1$ & $21,78 \mathrm{~h}-1$ & 2,64 & 21,50 \\
Gilirang & $22,11 \mathrm{~g}-1$ & $22,22 \mathrm{f}-\mathrm{k}$ & 0,50 & 22,17 \\
Cimelati & $26,56 \mathrm{a}-\mathrm{d}$ & $26,33 \mathrm{a}-\mathrm{d}$ & $-0,87$ & 26,45 \\
Fatmawati & $28,22 \mathrm{ab}$ & $22,44 \mathrm{f}-\mathrm{k}$ & $-20,48$ & 25,33 \\
\hline Rerata & $\mathbf{2 3 , 1 5}$ & $\mathbf{2 3 , 5 9}$ & & $(+)$ \\
\hline
\end{tabular}

KK $(\%)=19,35$

Keterangan : Angka yang diikuti huruf yang sama dalam baris dan kolom tidak berbeda nyata menurut DMRT 5\%. Tanda (+) menunjukkan ada interaksi.

\section{Jumlah gabah isi per malai}

Berdasarkan hasil analisis data jumlah gabah isi per malai dipengaruhi interaksi varietas dengan cara budidaya (Tabel 5).Jumlah gabah isi per malai semua varietas pada budidaya organik tidak berbeda dengan budidaya konvensional. Pada budidaya konvensional dan organik, jumlah gabah isi varietas Fatmawati terbanyak dan berbeda nyata dengan varietas yang lain. Hal ini karena terciptanya keserasian antara varietas Fatmawati dengan lingkungan sehingga mampu menjalankan proses fisiologis dengan baik (Guswara, 2003), termasuk translokasi asimilat dari daun ke gabah sehingga menyebabkan 
JURNAL ILMIAH AGRINECA

ISSN : 2721-074X (Online) - 2301-6698 (Print) Available on : http://ejournal.utp.ac.id/index.php/AFP/index

This is Under CC BY SA Licence

jumlah gabah isi per malai meningkat

(Setiobudi dan Sembiring, 2009).

Tabel 5. Rerata jumlah gabah isi per malai 15 varietas padi sawah pada budidaya organik dan konvensional

\begin{tabular}{|c|c|c|c|c|}
\hline \multirow[t]{2}{*}{ Varietas } & \multicolumn{2}{|c|}{ Budidaya (B) } & \multirow{2}{*}{$\begin{array}{c}\% \\
\text { Peningkatan } \\
\text { dari Bk ke Bo }\end{array}$} & \multirow[t]{2}{*}{ Rerata } \\
\hline & $\begin{array}{c}\text { Konvensional } \\
\text { (Bk) }\end{array}$ & $\begin{array}{l}\text { Organik } \\
\text { (Bo) }\end{array}$ & & \\
\hline Mentikwangi & $92,44 d-j$ & $100,45 \mathrm{c}-\mathrm{i}$ & 7,97 & 96,44 \\
\hline Mentiksusu & $108,45 \mathrm{c}-\mathrm{h}$ & $122,11 \mathrm{~cd}$ & 12,60 & 115,28 \\
\hline Pandanwangi & $98,22 \mathrm{~d}-\mathrm{j}$ & $95,11 \mathrm{~d}-\mathrm{j}$ & $-3,17$ & 96,66 \\
\hline Rojolele & $76,22 \mathrm{~h}-\mathrm{j}$ & $66,56 j$ & $-12,67$ & 71,39 \\
\hline Cianjur & $103,44 \mathrm{c}-\mathrm{i}$ & $84,56 \mathrm{e}-\mathrm{j}$ & 18,25 & 94,00 \\
\hline Pelita I-1 & 115,89 c-e & $111,67 \mathrm{c}-\mathrm{g}$ & $-4,22$ & 113,78 \\
\hline Remaja & $99,55 \mathrm{c}-\mathrm{i}$ & $81,45 \mathrm{~g}-\mathrm{j}$ & $-18,18$ & 90,50 \\
\hline IR64 & $104,56 \mathrm{c}-\mathrm{i}$ & $100,56 \mathrm{c}-\mathrm{i}$ & $-3,83$ & 102,56 \\
\hline Situbagendit & $105,67 \mathrm{c}-\mathrm{i}$ & $74,56 \mathrm{ij}$ & $-29,44$ & 90,11 \\
\hline Cisedane & $109,89 \mathrm{c}-\mathrm{g}$ & $82,56 \mathrm{f}-\mathrm{j}$ & $-24,87$ & 96,22 \\
\hline Ciherang & $115,44 \mathrm{c}-\mathrm{f}$ & $98,44 \mathrm{~d}-\mathrm{j}$ & $-14,73$ & 106,94 \\
\hline Inpari13 & $97,22 \mathrm{~d}-\mathrm{j}$ & $106,11 \mathrm{c}-\mathrm{i}$ & 9,14 & 101,67 \\
\hline Gilirang & $124,89 \mathrm{~cd}$ & $123,45 \mathrm{~cd}$ & $-1,15$ & 124,17 \\
\hline Cimelati & $132,55 \mathrm{bc}$ & $117,44 \mathrm{c}-\mathrm{e}$ & $-11,40$ & 124,99 \\
\hline Fatmawati & $163,89 \mathrm{a}$ & $158,89 \mathrm{a}$ & $-3,05$ & 161,39 \\
\hline Rerata & 109,89 & 101,59 & & $(+)$ \\
\hline
\end{tabular}

$\mathrm{KK}(\%)=15,61$

Keterangan : Angka yang diikuti huruf yang sama dalam baris dan kolom tidak berbeda nyata menurut DMRT 5\%. Tanda (+) menunjukkan ada interaksi.

\section{Berat 1000 gabah}

Berdasarkan hasil analisis data menunjukkan berat 1000 gabah dipengaruhi interaksi varietas dengan cara budidaya (Tabel 6). Berat 1000 gabah pada budidaya organik tidak berbeda dengan budidaya konvensional kecuali varietas Pelita I-1, hal ini karena berat 1000 gabah cenderung dipengaruhi oleh faktor genetik suatu varietas dibandingkan faktor lingkungan (Horie et al., 2006).Berat 1000 gabah varietas Pelita I-1 pada budidaya organik lebih besar dibandingkan budidya konvensional, hal ini diduga dipengaruhi oleh faktor lingkungan terutama unsur hara. Hal ini karena terciptanya keserasian antara varietas Pelita I-1 dengan lingkungan sehingga mampu menjalankan proses fisiologis lebih baik (Guswara, 2003), termasuk translokasi asimilat dari daun ke gabah sehingga menyebabkan berat 1000 gabah meningkat (Setiobudi dan Sembiring, 2009). Pada budidaya organik maupun konvensional, berat 1000 gabah terbesar varietas Rojolele yang merupakan varietas lokal, hal ini sesuai dengan deskripsi varietas yang menyatakan berat 1000 gabah varietas Rojolele 32 gram dan paling besar dibandingkan dengan varietas yang lain.

Tabel 6. Rerata berat 1000 gabah (g) 15 varietas padi sawah pada budidaya organik dan konvensional

\begin{tabular}{|c|c|c|c|c|}
\hline \multirow[t]{2}{*}{ Varietas } & \multicolumn{2}{|c|}{ Budidaya (B) } & \multirow{2}{*}{$\begin{array}{c}\% \\
\text { Peningkatan } \\
\text { dari Bk ke Bo }\end{array}$} & \multirow[t]{2}{*}{ Rerata } \\
\hline & $\begin{array}{c}\text { Konvensional } \\
(\mathrm{Bk})\end{array}$ & $\begin{array}{l}\text { Organik } \\
\text { (Bo) }\end{array}$ & & \\
\hline Mentikwangi & $23,96 \mathrm{c}$ & $24,00 \mathrm{c}$ & 0,17 & 23,98 \\
\hline Mentiksusu & $20,20 \mathrm{f}-\mathrm{h}$ & $21,61 \mathrm{f}-\mathrm{h}$ & 6,98 & 20,91 \\
\hline Pandanwangi & $24,95 \mathrm{~b}$ & $24,95 \mathrm{~b}$ & 0 & 24,95 \\
\hline
\end{tabular}


JURNAL ILMIAH AGRINECA

ISSN : 2721-074X (Online) - 2301-6698 (Print) Available on : http://ejournal.utp.ac.id/index.php/AFP/index

This is Under CC BY SA Licence

\begin{tabular}{llccc}
\hline Rojolele & $29,96 \mathrm{a}$ & $30,11 \mathrm{a}$ & 0,50 & 30,04 \\
Cianjur & $23,11 \mathrm{~d}$ & $23,13 \mathrm{~d}$ & 0,09 & 23,12 \\
Pelita I-1 & $19,77 \mathrm{gh}$ & $21,16 \mathrm{e}$ & 7,03 & 20,47 \\
Remaja & $25,28 \mathrm{~b}$ & $25,30 \mathrm{~b}$ & 0,08 & 25,29 \\
IR64 & $22,37 \mathrm{~d}$ & $22,58 \mathrm{~d}$ & 0,94 & 22,48 \\
Situbagendit & $24,46 \mathrm{bc}$ & $24,45 \mathrm{bc}$ & $-0,04$ & 24,45 \\
Cisedane & $22,77 \mathrm{~d}$ & $22,87 \mathrm{~d}$ & 0,44 & 22,82 \\
Ciherang & $25,24 \mathrm{~b}$ & $25,25 \mathrm{~b}$ & 0,04 & 25,24 \\
Inpari13 & $23,00 \mathrm{~d}$ & $23,14 \mathrm{~d}$ & 0,61 & 23,07 \\
Gilirang & $22,78 \mathrm{~d}$ & $22,86 \mathrm{~d}$ & 0,35 & 22,82 \\
Cimelati & $20,60 \mathrm{e}-\mathrm{g}$ & $20,64 \mathrm{ef}$ & 0,19 & 20,62 \\
Fatmawati & $19,68 \mathrm{~h}$ & $19,67 \mathrm{~h}$ & $-0,05$ & 19,67 \\
\hline Rerata & $\mathbf{2 3 , 2 1}$ & $\mathbf{2 3 , 4 5}$ & & $(+)$ \\
\hline
\end{tabular}

$\mathrm{KK}(\%)=0,56$

Keterangan: Angka yang diikuti huruf yang sama dalam baris dan kolom tidak berbeda nyata menurut DMRT 5\%. Tanda (+) menunjukkan ada interaksi.

\section{Berat gabah per rumpun}

Berdasarkan hasil analisis data terdapat interaksi antara varietas dengan cara budidaya pada berat gabah per rumpun (Tabel 7). Budidaya organik menurunkan berat gabah per rumpun varietas Pandanwangi, Rojolele, dan Ciherang.Hal ini karena jumlah malai varietas Pandanwangi dan Ciherang menurun pada budidaya secara organik. Pada budidaya konvensional, berat gabah per rumpun tertinggi dimiliki varietas Situbagendit yang berbeda nyata dengan varietas Mentikwangi, Mentiksusu, Pelita I-1, Cisedane, dan Cimelati, namun pada budidaya organik berat gabah per rumpun tertinggi dimiliki varietas Situbagendit yang berbeda nyata dengan varietas
Mentiksusu, Pandanwangi, Rojolele, Remaja, Cisedane, Ciherang, Gilirang, dan Cimelati.

Varietas IR64 mempunyai hasil tinggi pada budidaya konvensional dan tidak menurun hasil bila dibudidayakan secara organik.Hal ini terjadi karena varietas IR64 tidak menurun jumlah malainya bila dibudidayakan secara organik (Tabel 3).Varietas Pandanwangi yang mempunyai jumlah malai sangat banyak pada budidaya secara konvensional, pada budidaya organik jumlah malainya menurun secara nyata. Varietas IR64 maupun Pandanwangi tidak menurun jumlah gabah isi per malai dan berat 1000 gabah saat dibudidayakan secara organik

Tabel 7. Rerata hasil gabah per rumpun (g) 15 varietas padi sawah pada budidaya organik dan konvensional

\begin{tabular}{|c|c|c|c|c|}
\hline \multirow{3}{*}{ Varietas } & \multicolumn{3}{|c|}{ Budidaya } & \multirow{3}{*}{ Rerata } \\
\hline & \multicolumn{2}{|c|}{ Konvensional } & \multirow[t]{2}{*}{ Organik } & \\
\hline & Hasil & Harkat *) & & \\
\hline Mentikwangi & $21,45 \mathrm{~cd}$ & Sangat rendah & $25,37 \mathrm{~b}-\mathrm{d}$ & 23,41 \\
\hline Mentiksusu & $24,01 \mathrm{~cd}$ & Sangat rendah & $22,29 \mathrm{~cd}$ & 23,15 \\
\hline Pandanwangi & $38,80 \mathrm{ab}$ & Sangat tinggi & $12,60 \mathrm{~d}$ & 25,70 \\
\hline Rojolele & $32,89 \mathrm{a}-\mathrm{c}$ & Sedang & $21,87 \mathrm{~d}$ & 27,38 \\
\hline Cianjur & $40,28 \mathrm{a}$ & Sangat tinggi & 32,56 a-c & 36,42 \\
\hline Pelita I-1 & $21,89 \mathrm{~cd}$ & Sangat rendah & $25,47 \mathrm{~b}-\mathrm{d}$ & 23,68 \\
\hline Remaja & 30,38 a-c & Sedang & $22,98 \mathrm{~cd}$ & 26,68 \\
\hline IR64 & $40,85 \mathrm{a}$ & Sangat tinggi & $33,95 \mathrm{a}-\mathrm{c}$ & 37,40 \\
\hline Situbagendit & $41,24 \mathrm{a}$ & Sangat tinggi & $39,86 \mathrm{ab}$ & 40,55 \\
\hline Cisedane & $25,53 \mathrm{~b}-\mathrm{d}$ & Rendah & $19,39 \mathrm{~cd}$ & 22,46 \\
\hline
\end{tabular}


JURNAL ILMIAH AGRINECA

ISSN : 2721-074X (Online) - 2301-6698 (Print) Available on : http://ejournal.utp.ac.id/index.php/AFP/index

This is Under CC BY SA Licence

\begin{tabular}{llllc} 
& & & & \\
\hline Ciherang & $32,52 \mathrm{a}-\mathrm{c}$ & Sedang & $12,39 \mathrm{~d}$ & 22,46 \\
Inpari13 & $40,35 \mathrm{a}$ & Sangat tinggi & $31,33 \mathrm{a}-\mathrm{c}$ & 35,84 \\
Gilirang & $33,66 \mathrm{a}-\mathrm{c}$ & Tinggi & $22,74 \mathrm{~cd}$ & 28,20 \\
Cimelati & $22,50 \mathrm{~cd}$ & Sangat rendah & $18,97 \mathrm{~cd}$ & 20,74 \\
Fatmawati & $28,96 \mathrm{a}-\mathrm{c}$ & Rendah & $30,33 \mathrm{a}-\mathrm{c}$ & 29,65 \\
\hline Rerata & $\mathbf{3 1 , 6 9}$ & & $\mathbf{2 4 , 8 1}$ & $(+)$ \\
\hline
\end{tabular}

$\mathrm{KK}(\%)=28,42$

*) menurut Aturan Sturges (Sudjana, 2001)

Kelas interval dan harkat hasil padi sawah disajikan pada Tabel 8.

Keterangan : Angka yang diikuti huruf yang sama dalam baris dan kolom tidak berbeda nyata menurut DMRT 5\%. Tanda (+) menunjukkan ada interaksi.

Tabel 8. Kelas interval dan harkat hasil padi sawah menurut Aturan Sturges (Sudjana, 2001)

$$
\text { Kelas interval Harkat Hasil }
$$

\begin{tabular}{ll}
\hline 21,45 s.d. 25,50 & Sangat Rendah \\
25,50 s.d. 29,55 & Rendah \\
29,55 s.d. 33,60 & Sedang \\
33,60 s.d. 37,65 & Tinggi \\
37,65 & Sangat tinggi \\
\hline
\end{tabular}

Varietas Mentikwangi cenderung meningkat hasilnya bila dibudidayakan secara organik.Hal ini terjadi karena pada budidaya organik, varietas Mentikwangi cenderung meningkat jumlah gabah isi per malai.Varietas Cisedane cenderung menurun jumlah gabah isi pada budidaya organik karena panjang malai cenderung lebih pendek.Varietas Mentikwangi dan Cisedane tidak menurun berat 1000 gabah saat dibudidayakan secara organik

Tabel 9. Rerata perubahan hasil gabah per rumpun (g) 15 varietas padi sawah dari budidaya konvensional ke budidaya organik

\begin{tabular}{lccl}
\multicolumn{1}{c}{ Varietas } & $\begin{array}{c}\text { Perubahan hasil } \\
\text { Mentikwangi }\end{array}$ & $(\mathrm{g})$ & \multicolumn{1}{c}{ Perubahan hasil } \\
\cline { 3 - 4 } Mentiksusu & 3,92 & 18,3 & Sangat kecil \\
Pandanwangi & $-1,72$ & $-7,2$ & Kecil \\
Rojolele & $-26,20$ & $-67,5$ & Sangat besar \\
Cianjur & $-11,02$ & $-33,5$ & Sedang \\
Pelita I-1 & $-7,72$ & $-19,2$ & Sedang \\
Remaja & 3,58 & 16,4 & Sangat kecil \\
IR64 & $-7,40$ & $-24,4$ & Sedang \\
Situbagendit & $-6,90$ & $-16,9$ & Sedang \\
Cisedane & $-1,38$ & $-3,3$ & Kecil \\
Ciherang & $-6,14$ & $-24,0$ & Sedang \\
Inpari13 & $-20,13$ & $-61,9$ & Sangat besar \\
Gilirang & $-9,02$ & $-22,4$ & Sedang \\
Cimelati & $-10,92$ & $-32,4$ & Sedang \\
Fatmawati & $-3,53$ & $-15,7$ & Kecil \\
\hline Keterangan & 1,37 & 4,7 & Sangat kecil
\end{tabular}

Keterangan :

$+=$ ada peningkatan hasil dari budidaya konvensional ke budidaya organik .

- = ada pengurangan hasil dari budidaya konvensional ke budidaya organik.

*) Menurut aturan Sturges (Sudjana, 2001) 
JURNAL ILMIAH AGRINECA

ISSN : 2721-074X (Online) - 2301-6698 (Print)

Available on : http://ejournal.utp.ac.id/index.php/AFP/index

This is Under CC BY SA Licence

Kelas interval dan harkat selisih berat gabah per rumpun dari budidaya konvensional ke budidaya organik disajikan pada Tabel 9.

Berdasarkan Tabel 9, ada peningkatan hasil dari budidaya konvensional ke budidaya organik meliputi varietas Mentikwangi, Pelita I-1, Fatmawati, sedangkan varietas yang lain mengalami penurunan hasil. Varietas Mentikwangi merupakan varietas dengan peningkatan hasil terbesar $18,3 \%$ dan sebaliknya varietas Pandanwangi merupakan varietas dengan penurunan hasil terbesar $67,5 \%$

\section{KESIMPULAN}

Dari hasil pengamatan dapat disimpulkan bahwa berdasarkan hasilnya varietas Mentikwangi, Pelita I-1 dan Fatmawati merupakan varietas padi yang sesuai untuk budidaya organik

\section{UCAPAN TERIMA KASIH}

Terima kasih kami ucapkan kepada Kemenristekdikti yang telah membiayai penelitian ini pada Hibah Penelitian Disertasi Doktor, Rektor Universitas Tunas Pembangunan, Dekan Fakultas Pertanian UTP, kepala LPPM UTP Surakarta, dan Pak Blondo yang telah banyak membantu pada pelaksanaan di lapang.

\section{DAFTAR PUSTAKA}

Abdullah, B., Tjokrowidjojo, S., Kustianto, B., dan Daradjat, A.A. 2005. Pembentukan Varietas Unggul Tipe Baru Fatmawati. Jurnal Penelitian Pertanian Vol. 25 (1) : 1-7.

Allen, P and Dusen, V. D. 1988. Sustainable Agriculture : Choosing the Future. In : Global Perspective on Agroecology am Sustainable Agricultural Systems. University of California, Santa Cruz, CA. USA.
Dobermann, A., and Fairhurst, T. 2000. Rice, Nutrient Disorders and Nutrient Management.International Rice Research Institute and Potash \& Phosphate Institute of Canada.

Guswara, A., Tita, R., Sutisna, dan Las, I. 2003.Intersepsi radiasi dalam berbagai jarak tanam padi tipe baru.Laporan kemajuan Penelitian. Balai Besar Penelitian Tanaman Padi. Sukamandi. $11 \mathrm{p}$.

Hasanuzzaman, M., Ahamed, K.U., Rahmatullah, N.M., Akhter, N., Nahar, K., and Rahman, M.L. 2010.Plant Growth Characters and Productivity of Wetland Rice (Oryza sativa L.) as Affected by Application of Different Manures.Emir.Food Agricultural Journal. Vol. 22 (1) : 4658.

Horrie, T., Homma, K., and Yoshida, H. 2006. Physiological and morphological traits associated with high yield potential in Rice. Abstracts.Second International Rice Congress. 2006. $26^{\text {th }}$ International Rice Research Conference. P.12-13.

Ali, M. (2016). Pembuatan PGPR (Plant Growth Promoting Rhizobacteria) Dari Akar Bambu. Development of Agriculture, 2(1), 1-12.

Hariyadi, B. W., Huda, N., Ali, M., \& Wandik, E. (2019). The Effect of Tambsil Organic Fertilizer on The Growth And Results of Onion (Allium Ascalonicum L.) In Lowland. Agricultural Science, 2(2), 127-138.

Ikemura, Y., and Manoj Shukla, K. 2009. Soil Quality In Organic and Conventional Farms of New Mexico, USA. Journal of Organic Systems, Vol. 4 (1).

Khan, M. A., I., K. Ueno, S. Horimoto, F. Komai, K. Tanaka, and Y. Ono. 2007. Evaluation of the PhysioChemical and Microbial Properties of Green Tea Waste-Rice Bran Compost and the Effect of the Compost on Spinash Production. Plant Production Science Journal, Vol. 10 (4) : 301399. 


\section{AGRINECA}

\section{JURNAL ILMIAH AGRINECA}

ISSN : 2721-074X (Online) - 2301-6698 (Print)

Available on : http://ejournal.utp.ac.id/index.php/AFP/index

This is Under CC BY SA Licence

Matsuo, T and Hoshikawa, K. 1993. Science of the Rice Plant Volume I. Morphology.Food and Agriculture Policy Research Center. Tokyo. $685 \mathrm{p}$.

Murayama, N. 1995.Fertilizer Application to Rice in Relation to Nutriphysiology of Ripening.Journal Agricultural Science. Vol. 24 (2) : 71-77

Sanati, B. E., Daneshiyan, J., Amiri, E., and Azarpour, E. 2011. Study of organic Fertilizers Displacement in Rice Sustainable Agriculture. International Journal of Academic Research.Vol.3 (2).

SAS. 2002. Statistical Analysing System for Windows 9.0. SAS Institute Inc., SAS Campus Drive, Cary, North Carolina, USA.

Setiobudi, D, dan Sembiring, H. 2009. Tanggap pertumbuhan dan hasil padi tipe Baru terhadap pupuk makro dan mikro pada spesifik jenis tanah. Prosiding Penelitian tanaman padi. Balai Besar Penelitian Tanaman Padi. 2009.

Sudjana, 2001. Metode Statistika. Edisi ke-6. Tarsito Bandung. 508 hal. 